\title{
Bovine pericardial versus porcine stented replacement aortic valves: Early results of a randomized comparison of the Perimount and the Mosaic valves
}

John B. Chambers, MD, FACC, Ronak Rajani, MD, MRCP, Denise Parkin, RCN, Helen M. Rimington, PhD, Christopher I. Blauth, MS, FRCS, Graham E. Venn, FRCS, Christopher P. Young, FRCS, and James C. Roxburgh, FRCS

Objective: A stented bovine pericardial valve might be less obstructive than a stented porcine valve. This study compared early hemodynamic function in a prospective series of 99 patients randomized to receive either a Mosaic or Perimount replacement aortic valve.

Methods: Echocardiography was performed early after surgery and at 1 year after surgery. Patients also filled in psychologic questionnaires and underwent a 6-minute walk.

Results: The groups were matched demographically. The Perimount valve was significantly less obstructive in terms of mean pressure difference $(11 \pm 5$ vs $17 \pm 7 \mathrm{~mm}$ $\mathrm{Hg} ; P<.0001)$, with a trend in favor of a larger effective orifice area $(1.47 \pm 0.45 \mathrm{vs}$ $\left.1.28 \pm 0.46 \mathrm{~cm}^{2} ; P=.05\right)$ postoperatively. There were no differences in left ventricular mass regression, aortic regurgitation, 6-minute walk, psychologic questionnaires, or mortality and clinical events.

Conclusion: The stented bovine pericardial valve was less obstructive than the stented porcine valve. Both valves were associated with similar and significant improvements in quality of life, exercise ability, and regression of left ventricular mass.

From the Cardiothoracic Centre, Guy's and St Thomas' Hospitals, London, United Kingdom.

This study was funded with an unrestricted educational grant from Medtronic.

Received for publication Aug 11, 2007; revisions received Dec 10, 2007; accepted for publication Dec 27, 2007.

Address for reprints: John B. Chambers, MD, FACC, Cardiothoracic Centre, St Thomas' Hospital, London SE1 7EH, United Kingdom (E-mail: jboydchambers@aol.com).

J Thorac Cardiovasc Surg 2008;136:1142-8 $0022-5223 / \$ 34.00$

Copyright $(2008$ by The American Association for Thoracic Surgery

doi:10.1016/j.jtcvs.2007.12.086
$\mathrm{T}$ There is a perception that stented pericardial valves have better hemodynamic function than stented porcine valves. ${ }^{1-3}$ However, comparing studies is difficult because of differences in echocardiographic methods and the frequent reliance on flow-dependent measures of prosthetic valve function. Sizing conventions also differ between valve types so that it may not be appropriate to compare valves of the same label size. ${ }^{4}$ There are few randomized comparisons, and these give contradictory results, with a pericardial design either superior ${ }^{5}$ or similar $^{6}$ to a porcine valve.

We therefore designed a randomized trial to compare hemodynamic function in the Medtronic Mosaic porcine valve (Medtronic, Inc, St Paul, Minn) and the CarpentierEdwards Perimount bovine pericardial valve (Edwards Lifesciences, Irvine, Calif). Secondary end points were clinical event rates, exercise capacity, and measures of overall health in the first year after surgery.

\section{Methods}

\section{Patients}

A total of 100 consecutive patients scheduled to have single bioprosthetic valve replacement in the aortic position were randomized. All subjects were aged 19 to 90 years and none was undergoing redo valve surgery or had a preoperative creatinine value of more than $500 \mu \mathrm{mol} / \mathrm{L}$ or a coexistent illness known to have a significant mortality. After randomization, 1 patient received a mechanical valve because of an aberrant origin of both coronary arteries, which left a population of 99 . Of these, because of procedural difficulties, 2 patients randomized to receive a Perimount valve received a Mosaic valve and 1 randomized to receive a Mosaic valve received 


\section{Abbreviations and Acronyms \\ $\mathrm{LV}=$ left ventricular \\ NS $=$ no significant difference \\ NYHA $=$ New York Heart Association \\ $\mathrm{SD}=$ standard deviation \\ SF-36 = Short Form-36 health questionnaire}

a Perimount instead. The study population comprised 51 with a Mosaic and 48 with a Perimount valve. The mean age was 75.5 years (range 58-89 years) and $61(60 \%)$ were male (Table 1). The study was accepted by the local committee on ethical practice and all patients gave written informed consent.

\section{Surgery}

Both valves were implanted according to their manufacturer's recommendations, giving a supra-annular position for the Mosaic and a partially supra-annular position for the Perimount valves. The number on the sizers of the Mosaic bioprosthesis denotes the size of the valve to be used in the supra-annular position, so that the label size is expected to be larger than the annulus diameter. By contrast,

\section{TABLE 1. Demographic data}

\begin{tabular}{|c|c|c|}
\hline & Mosaic & Perimount \\
\hline $\mathrm{N}$ & 51 & 48 \\
\hline Age (y) & $77(61-89)$ & $75(58-88)$ \\
\hline Male/female & $30: 21$ & $31: 17$ \\
\hline \multicolumn{3}{|l|}{ Etiology } \\
\hline AS & 45 & 44 \\
\hline $\mathrm{AR}$ & 3 & 2 \\
\hline Mixed AVD & 3 & 2 \\
\hline $\begin{array}{l}\text { Previous cardiac } \\
\text { procedures }\end{array}$ & 0 & 2 (1 CABG, 1 PPM) \\
\hline $\begin{array}{l}\text { Effective orifice area } \\
\qquad\left(\mathrm{cm}^{2}\right)\end{array}$ & $0.83 \pm 0.51$ & $0.75 \pm 0.41$ \\
\hline $\begin{array}{l}\text { Mean pressure drop } \\
(\mathrm{mm} \mathrm{Hg})\end{array}$ & $47 \pm 20$ & $43 \pm 18$ \\
\hline $\begin{array}{l}\text { Concomitant } \\
\text { procedures }\end{array}$ & $26 \mathrm{CABG}$ & $\begin{array}{l}23 \text { CABG, } 1 \text { aortic root } \\
\text { replacement }\end{array}$ \\
\hline \multicolumn{3}{|l|}{ Preop NYHA } \\
\hline I & 7 & 2 \\
\hline II & 24 & 20 \\
\hline III & 20 & 24 \\
\hline IV & 0 & 2 \\
\hline Height $(\mathrm{cm})$ & $167 \pm 9$ & $166 \pm 8$ \\
\hline Weight (kg) & $74 \pm 13$ & $74 \pm 14$ \\
\hline $\mathrm{BSA}\left(\mathrm{m}^{2}\right)$ & $1.82 \pm 0.19$ & $1.82 \pm 0.19$ \\
\hline BMI & $26.8 \pm 3.8$ & $26.5 \pm 4.5$ \\
\hline EuroSCORE & $8 \pm 5$ & $8 \pm 4$ \\
\hline Parsonnet & $20 \pm 8$ & $21 \pm 8$ \\
\hline
\end{tabular}

$A S$, Aortic stenosis; $A R$, aortic regurgitation; $A V D$, aortic valve disease; $C A B G$, coronary artery bypass grafting; $P P M$, permanent pacemaker; NYHA, New York Heart Association; BSA, body surface area; BMI, body mass index. the number on the sizer of the Perimount bioprosthesis denotes the size of the valve to be used in the intra-annular position. A universal sizer (graduated in millimeters) was therefore used to determine the actual diameter of the patient tissue annulus and then both the Perimount and Mosaic sizers were used before the randomization envelope was opened. The surgeon implanted the valve by his routine technique using noneverting, vertical mattress sutures $(n=78)$ or continuous sutures $(n=21)$.

\section{Echocardiography}

The majority of studies were performed by one sonographer (H.M.R.) immediately postoperatively and at 1 year (10-14 months) using a Vivid-7 system (GE Medical, Milwaukee, Wis). All patients had a postoperative study, but 22 did not have a study at 1 year (11 dead, 3 agreed to telephone follow-up only, 1 declined all follow-up, 5 were unable to travel because of illness, and 2 were completely lost to follow-up). Measurements were made as recommended by the American Society of Echocardiography ${ }^{7}$ over 3 cycles in sinus rhythm or over 6 cycles in atrial fibrillation. Regurgitant jets were localized, then graded by a combination of the diameter of the base of the jet, and the density and slope of the aortic regurgitant signal recorded by continuous wave Doppler sonography. Mild regurgitation was defined by a jet height less than $25 \%$ of the outflow diameter and a complete, low-intensity continuous waveform with pressure half-time longer than $500 \mathrm{~ms}$. Trivial regurgitation was defined by a thin low-momentum jet ending close to the valve with an incomplete continuous waveform. No jet in this study was found to be moderate or severe.

\section{Calculations}

The following calculations were performed: effective orifice area by the continuity equation $\left(\mathrm{EOA}\right.$ in $\left.\mathrm{cm}^{2}\right)=\mathrm{CSA} \times \mathrm{VTI}_{1} / \mathrm{VTI}_{2}$, where CSA is left ventricular (LV) outflow cross-sectional area $\left(\mathrm{cm}^{2}\right)$ calculated from the diameter assuming circular cross section, $\mathrm{VTI}_{1}$ is subaortic velocity integral $(\mathrm{cm})$, and $\mathrm{VTI}_{2}$ is aortic velocity integral $(\mathrm{cm})$; peak pressure difference across the aortic valve (peak $\Delta \mathrm{P}$ in $\mathrm{mm} \mathrm{Hg})=4\left(\mathrm{v}_{2}{ }^{2}-\mathrm{v}_{1}{ }^{2}\right)$ where $\mathrm{v}_{2}$ is transaortic peak velocity $(\mathrm{m} / \mathrm{s})$ and $\mathrm{v}_{1}$ is subaortic peak velocity $(\mathrm{m} / \mathrm{s})$; mean pressure difference across the aortic valve (mean $\Delta \mathrm{P}$ in $\mathrm{mm} \mathrm{Hg}$ ) $=$ aortic mean $\Delta \mathrm{P}-$ subaortic mean $\triangle \mathrm{P}$; LV mass $(\mathrm{gm})=0.83(\mathrm{LVDD}+\mathrm{IVS}+$ $\mathrm{PW})^{3}-(\mathrm{LVDD})^{3}$, where LVDD is left ventricular diastolic diameter, IVS is interventricular septal width, and Posterior Wall width (PW) is .... Effective orifice area and LV mass were indexed to body surface area. Patient-prosthesis mismatch was defined by an indexed effective orifice area (EOAi) $<0.85 \mathrm{~cm}^{2} / \mathrm{m}^{2}$ and severe mismatch by EOAi $<0.65 \mathrm{~cm}^{2} / \mathrm{m}^{2}$.

\section{Clinical Events}

Patients were interviewed at 3 to 6 months and at 1 year. The definitions used were as recommended by the guidelines of The Society of Thoracic Surgeons and the American Association for Thoracic Surgery. ${ }^{8}$ If the exact timing of an event was not known, it was taken as perioperative if noted at the immediate postoperative visit. It was recorded as at the midpoint between two visits if absent at the first and present at the second. Early events occurred in the first 30 days and late events between 30 days and 12 months. Dysarrhythmic deaths after recovery from the anesthetic but before discharge were included as valve-related. Dysarrhythmias after surgery were 
not included as complications if already apparent before surgery. Late events were collected by telephone at 6 months and by questionnaire at the time of the 12-month echocardiogram

\section{Functional Assessment}

The Short Form-36 (SF-36) health questionnaire ${ }^{9,10}$ and the Hospital Anxiety and Depression scale ${ }^{11}$ were given preoperatively (within 6 weeks assuming no new clinical event) and at 1 year (10 and 14 months). The mental composite score and physical composite score of the SF-36 questionnaire were calculated. ${ }^{9}$ New York Heart Association (NYHA) class was recorded. In addition, the 6minute walk was recorded before surgery and at 1 year. This test has been validated for patients with heart failure and lung disease. ${ }^{12}$ It is suitable for elderly persons who may not be able to use either a bicycle or treadmill and has physiologic validity in allowing the subject to walk at his or her own pace. The distance walked was recorded by the investigator walking with the patient and pushing a pedometer.

\section{Analysis}

A sample size of 45 per group was expected to allow detection of a 5 $\mathrm{mm} \mathrm{Hg}$ difference in mean gradient with $90 \%$ power. The mean and standard deviation (SD) values were calculated for variables that were normally distributed and the median and range for those that were skewed. Clinical events were expressed as a proportion of the whole population and the incidence of regurgitation was expressed as a proportion of those having echocardiograms. Comparisons were made between valve types using the unpaired $t$ test or nonparametric Mann-Whitney $U$ test as appropriate, with analyses both by intention to treat and actual valve implanted. There were no material differences between the two analyses, so the analysis by actual valve implanted was reported. There were no missing data points for those echocardiographic studies performed. The incidence of regurgitation was compared by the Fisher exact test. Analyses were performed by the Statistical Package for Social Sciences version 11.5.1 for Windows (SPSS, Inc, Chicago, Ill).

\section{Results}

The patients were similar in terms of preoperative characteristics (Table 1). Crossclamp time was similar, 74 (SD 25) minutes for the Mosaic and 72 (SD 17) minutes for the Perimount bioprostheses. Total bypass time was also similar, 95 (SD 31) minutes for the Mosaic and 95 (SD 30) for the Perimount valves. The label sizes for the two valve designs were similar and on average approximately $1 \mathrm{~mm}$ smaller than the tissue annulus diameter determined by the independent sizer (Table 2).

For peak and mean transvalve pressure difference, there were small but statistically significant differences in favor of the Perimount valve both postoperatively and at 1 year. The effective orifice area was slightly larger in the Perimount valve postoperatively, but there was no significant difference (NS) at 1 year (Table 3 ). These differences were also apparent in the valves when compared by label size (Table 4). Patientprosthesis mismatch occurred in $40(82 \%)$ Mosaic compared with $30(64 \%)$ Perimount valves (NS). Severe mismatch
TABLE 2. Comparison between tissue annulus diameter and label size for the Mosaic and Perimount valves

\begin{tabular}{lccccc}
\hline & \multicolumn{2}{c}{ Mosaic implanted } & & \multicolumn{2}{c}{ Perimount implanted } \\
\cline { 2 - 3 } \cline { 5 - 6 } $\begin{array}{c}\text { Tissue } \\
\text { annulus }\end{array}$ & $\begin{array}{c}\text { Mosaic } \\
\text { sizer }\end{array}$ & $\begin{array}{c}\text { Perimount } \\
\text { sizer }\end{array}$ & & $\begin{array}{c}\text { Mosaic } \\
\text { sizer }\end{array}$ & $\begin{array}{c}\text { Perimount } \\
\text { sizer }\end{array}$ \\
\hline 19 & $19.0(0.0)$ & $19.0(0.0)$ & & $19.0(0.0)$ & $19.0(0.0)$ \\
20 & $19.0(0.0)$ & $19.0(0.0)$ & & - & - \\
21 & $20.6(0.8)$ & $20.6(0.8)$ & & $20.8(0.6)$ & $20.8(0.6)$ \\
22 & $21.0(0.0)$ & $21.0(0.0)$ & & $21.0(0.0)$ & $21.0(0.0)$ \\
23 & $22.3(1.0)$ & $22.3(1.0)$ & & $22.4(1.0)$ & $22.6(1.2)$ \\
24 & $21.5(1.0)$ & $22.0(1.2)$ & & $23.0(1.6)$ & $22.5(1.0)$ \\
25 & $24.1(1.1)$ & $24.1(1.1)$ & & $24.2(1.1)$ & $24.2(1.1)$ \\
26 & - & - & & - & - \\
27 & $26.0(1.4)$ & $26.0(1.4)$ & $26.0(1.4)$ & $26.0(1.4)$ \\
28 & - & - & $27.0(0.0)$ & $27(0.0)$ \\
29 & $28.0(1.4)$ & $28.0(1.4)$ & $25.5(1.0)$ & $25.5(1.0)$ \\
\hline
\end{tabular}

occurred in 22 (45\%) Mosaic compared with 14 (30\%) Perimount valves (NS).

At 1 year there was trivial or mild regurgitation through the valve in 8 Mosaic and 13 Perimount valves (NS) and trivial or mild paraprosthetic regurgitation in 4 Mosaic and 2 Perimount valves (NS). One valve in each group had regurgitant jets in both a paraprosthetic position and through the valve. Only one of the paraprosthetic jets was associated with continuous sutures.

There were no differences in preoperative or postoperative LV dimensions, LV mass index, fractional shortening, or LV outflow velocity integrals between the Mosaic and Perimount groups (Table 5). The ejection fraction was above 50\% in 44 (88\%) Mosaic and $38(81 \%)$ Perimount valves and below $30 \%$ in 1 Mosaic and 2 Perimount valves.

There were no statistically significant differences in mortality and clinical events between the two valve types. There was 1 early death (within 30 days) in the Mosaic group and 1

TABLE 3. Hemodynamic function postoperatively and at 1 year

\begin{tabular}{lccc}
\hline \multicolumn{1}{c}{ Variable } & Mosaic & Perimount & $\boldsymbol{P}$ value \\
\hline Postop & & & \\
$\mathrm{N}$ & 49 & 47 & \\
EOA $\left(\mathrm{cm}^{2}\right)$ & $1.28 \pm 0.46$ & $1.47 \pm 0.45$ & .05 \\
Peak $\Delta \mathrm{P}(\mathrm{mm} \mathrm{Hg})$ & $28 \pm 13$ & $19 \pm 9$ & $<.0001$ \\
Mean $\Delta \mathrm{P}(\mathrm{mm} \mathrm{Hg})$ & $17 \pm 7$ & $11 \pm 5$ & $<.0001$ \\
One year & & & \\
$\mathrm{N}$ & 40 & 37 & \\
EOA $\left(\mathrm{cm}^{2}\right)$ & $1.33 \pm 0.31$ & $1.42 \pm 0.46$ & $\mathrm{NS}$ \\
Peak $\Delta \mathrm{P}(\mathrm{mm} \mathrm{Hg})$ & $28 \pm 11$ & $19 \pm 8$ & $<.0001$ \\
Mean $\Delta \mathrm{P}(\mathrm{mm} \mathrm{Hg})$ & $15 \pm 6$ & $11 \pm 4$ & $<.0001$ \\
\hline
\end{tabular}

$E O A$, Effective orifice area by the continuity equation; $\Delta P$, pressure difference; $N S$, not significant. 
TABLE 4. Hemodynamic function (mean \pm standard deviation) postoperatively by label size

\begin{tabular}{|c|c|c|c|}
\hline Label size & Mosaic & Perimount & $P$ value \\
\hline 19 & $\mathrm{n}=5$ & $\mathrm{n}=4$ & \\
\hline $\mathrm{EOA}\left(\mathrm{cm}^{2}\right)$ & $0.93 \pm 0.34$ & $1.10 \pm 0.29$ & NS \\
\hline $\mathrm{EOAi}\left(\mathrm{cm}^{2}\right)$ & $0.58 \pm 0.24$ & $0.67 \pm 0.17$ & NS \\
\hline Peak $\Delta \mathrm{P}(\mathrm{mm} \mathrm{Hg})$ & $42 \pm 15$ & $31 \pm 8$ & NS \\
\hline Mean $\Delta \mathrm{P}(\mathrm{mm} \mathrm{Hg})$ & $23 \pm 8$ & $16 \pm 4$ & NS \\
\hline 21 & $\mathrm{n}=19$ & $\mathrm{n}=19$ & \\
\hline $\mathrm{EOA}\left(\mathrm{cm}^{2}\right)$ & $1.13 \pm 0.37$ & $1.27 \pm 0.25$ & NS \\
\hline EOAi $\left(\mathrm{cm}^{2}\right)$ & $0.63 \pm 0.26$ & $0.72 \pm 0.16$ & NS \\
\hline Peak $\Delta \mathrm{P}(\mathrm{mm} \mathrm{Hg})$ & $34 \pm 11$ & $22 \pm 7$ & .001 \\
\hline Mean $\Delta \mathrm{P}(\mathrm{mm} \mathrm{Hg})$ & $19 \pm 7$ & $13 \pm 5$ & .003 \\
\hline 23 & $\mathrm{n}=17$ & $\mathrm{n}=15$ & \\
\hline $\mathrm{EOA}\left(\mathrm{cm}^{2}\right)$ & $1.43 \pm 0.41$ & $1.71 \pm 0.42$ & NS \\
\hline EOAi $\left(\mathrm{cm}^{2}\right)$ & $0.80 \pm 0.24$ & $0.91 \pm 0.23$ & NS \\
\hline Peak $\Delta \mathrm{P}(\mathrm{mm} \mathrm{Hg})$ & $24 \pm 10$ & $14 \pm 6$ & .003 \\
\hline Mean $\Delta \mathrm{P}(\mathrm{mm} \mathrm{Hg})$ & $13 \pm 6$ & $8 \pm 4$ & .005 \\
\hline 25 & $\mathrm{n}=7$ & $\mathrm{n}=6$ & \\
\hline $\mathrm{EOA}\left(\mathrm{cm}^{2}\right)$ & $1.29 \pm 0.60$ & $1.43 \pm 0.55$ & NS \\
\hline EOAi $\left(\mathrm{cm}^{2}\right)$ & $0.79 \pm 0.23$ & $0.77 \pm 0.28$ & NS \\
\hline Peak $\Delta \mathrm{P}(\mathrm{mm} \mathrm{Hg})$ & $19 \pm 6$ & $18 \pm 10$ & NS \\
\hline Mean $\Delta \mathrm{P}(\mathrm{mm} \mathrm{Hg})$ & $13 \pm 7$ & $10 \pm 6$ & NS \\
\hline 27 & $\mathrm{n}=1$ & $\mathrm{n}=3$ & \\
\hline $\mathrm{EOA}\left(\mathrm{cm}^{2}\right)$ & 1.60 & $2.13 \pm 0.45$ & - \\
\hline EOAi $\left(\mathrm{cm}^{2}\right)$ & 0.76 & $1.1 \pm 0.2$ & - \\
\hline Peak $\Delta \mathrm{P}(\mathrm{mm} \mathrm{Hg})$ & 15 & $13 \pm 7$ & - \\
\hline Mean $\Delta \mathrm{P}(\mathrm{mm} \mathrm{Hg})$ & 9 & $7 \pm 3$ & - \\
\hline 29 & 1 & & \\
\hline $\mathrm{EOA}\left(\mathrm{cm}^{2}\right)$ & 2.3 & & - \\
\hline EOAi $\left(\mathrm{cm}^{2}\right)$ & 1.25 & & - \\
\hline Peak $\Delta \mathrm{P}(\mathrm{mm} \mathrm{Hg})$ & 13 & & - \\
\hline Mean $\Delta \mathrm{P}(\mathrm{mm} \mathrm{Hg})$ & 7.2 & & - \\
\hline
\end{tabular}

$E O A$, Effective orifice area by the continuity equation; $E O A i$, indexed effective orifice area; $\Delta P$, pressure difference; $N S$, not significant.

in the Perimount group. There were 3 late deaths (between 30 days and 12 months) in the Mosaic group and 5 in the Perimount group. There were 3 perioperative strokes in the Mosaic group and 2 in the Perimount group. There were 2 early thromboembolic events in the Mosaic group and 1 in the Perimount group. There were 2 late thromboembolic events in the Mosaic and 1 in the Perimount group. There was no endocarditis or valve thrombosis.

\section{Functional Measures}

Six-minute walk distance for the Mosaic valve increased from $255 \mathrm{~m}$ (SD $119 \mathrm{~m}$ ) preoperatively to $366 \mathrm{~m}$ (SD 121 $\mathrm{m})$ postoperatively $(P<.0001)$. For the Perimount group, the preoperative walk distance of $223 \mathrm{~m}$ (SD $129 \mathrm{~m}$ ) increased to $334 \mathrm{~m}$ (SD $104 \mathrm{~m})(P=.002)$. There were 51 (SD 65\%) patients in NYHA class I at 1 year, 27 Mosaic and 24 Perimount. There were 25 (32\%) in class II, 12 Mosaic and 13 Perimount. Only 1 Mosaic and 2 Perimount valve recipients were in NYHA class III, and no patients were in class IV. There were no differences between the valve types either before or after surgery in terms of 6-minute walk distance or NYHA class.

There were improvements in both anxiety and depression scores after surgery for each valve design, but no difference between the valve designs (Table 6a). Similarly, both mental and physical composite scores on the SF-36 questionnaire improved after surgery but with no difference between the valve types (Table 6b). The change in physical score was greater than for mental score.

\section{Discussion}

This randomized study suggests better hemodynamic function in a pericardial compared with a porcine stented valve. The peak and mean pressure differences were statistically lower with the pericardial valve $(P<.0001)$ both postoperatively and at 1 year although the clinical difference was relatively small, $6 \mathrm{~mm} \mathrm{Hg}$ in the mean and $9 \mathrm{~mm} \mathrm{Hg}$ in the peak pressure difference. Pressure difference is dependent on flow, but there was also a non-statistically significant trend to a larger effective orifice area in the pericardial valve both postoperatively (1.47 vs $1.28 \mathrm{~cm}^{2} ; P=.05$ ) and at 1 year $\left(1.42 \mathrm{vs} 1.33 \mathrm{~cm}^{2}\right)$ using the relatively flow-independent continuity equation. The incidence of patient-prosthesis mismatch was lower, $30(64 \%)$ for the pericardial Perimount compared with 40 (82\%) with the porcine Mosaic valve, although the difference was not statistically significant.

There were no discrepancies in the hemodynamic results in comparison with previously published studies of the Mosaic or Perimount valves. ${ }^{13-23}$ In general, nonrandomized studies tend to show better hemodynamic function for pericardial compared with porcine valves. Peak pressure difference for pericardial valves of label size $23 \mathrm{~mm}$ is around $15 \mathrm{~mm} \mathrm{Hg}{ }^{1}$ compared with a range of 18 to $32 \mathrm{~mm} \mathrm{Hg}$ for porcine valves of similar label size. ${ }^{2,3}$ However, variations in sizing convention mean that valves of different design with the same label size may fit different patient tissue annulus diameters, which necessitates randomization of two comparator valves. A study ${ }^{5}$ with a design similar to ours found that the mean pressure difference at rest was higher for the Mosaic valve at $14.6 \mathrm{~mm} \mathrm{Hg}$ than for the Perimount valve at $11.4 \mathrm{~mm} \mathrm{Hg}(P<.05)$. However, the mean effective orifice area was similar, $1.49 \mathrm{~cm}^{2}$ for the Mosaic and $1.56 \mathrm{~cm}^{2}$ for the Perimount valve. Seitelberger and associates ${ }^{6}$ also found that the Perimount was hemodynamically superior to the Mosaic bioprosthesis when compared by label size. However, hemodynamic function was similar when the two valve designs were compared according to patient tissue annulus. This result is different from ours and from the previous study by Eichinger and colleagues ${ }^{5}$ and may be explained by differences in sizing. The Mosaic valve is a true supra-annular design, whereas the Perimount pericardial bioprosthesis has an intra-annular stent design with a supra-annular cuff. This 
TABLE 5. Measure of left ventricular size and function (mean \pm SD)

\begin{tabular}{|c|c|c|c|c|c|c|}
\hline & Mosaic & & Perimount & & $95 \% \mathrm{CI}$ & $P$ value \\
\hline LVDD (cm) Pre & $5.1 \pm 0.86$ & 46 & $4.9 \pm 1.1$ & 46 & $-2.7,0.54$ & NS \\
\hline LVDD (cm) Post & $4.6 \pm 0.9$ & 49 & $4.7 \pm 0.9$ & 46 & $-0.52,0.17$ & NS \\
\hline LVDD (cm) $12 \mathrm{mo}$ & $4.5 \pm 0.8$ & 39 & $4.6 \pm 0.9$ & 36 & $-0.52,0.36$ & NS \\
\hline LVMI Pre & $233 \pm 123$ & 41 & $211 \pm 77$ & 44 & $-23,66$ & NS \\
\hline LVMI g/m² Post & $176 \pm 63$ & 46 & $183 \pm 59$ & 42 & $-33,19$ & NS \\
\hline LVMI g/m² $12 \mathrm{mo}$ & $152 \pm 50$ & 38 & $160 \pm 62$ & 36 & $-34,18$ & NS \\
\hline FS $(\%)$ Pre & $35 \pm 9$ & 42 & $32 \pm 11$ & 44 & $-2.1,6.7$ & NS \\
\hline FS (\%) Post & $31 \pm 10$ & 44 & $32 \pm 10$ & 38 & $-5.6,3.1$ & NS \\
\hline $\mathrm{FS}(\%) 12 \mathrm{mo}$ & $36 \pm 8$ & 36 & $34 \pm 10$ & 34 & $-2.2,6.6$ & NS \\
\hline LVOT VTI Pre & $21 \pm 5$ & 51 & $20 \pm 5$ & 48 & $-1,3$ & NS \\
\hline LVOT VTI Post & $17 \pm 4$ & 50 & $17 \pm 4$ & 47 & $-1,2$ & NS \\
\hline LVOT VTI 12 mo & $22 \pm 5$ & 40 & $20 \pm 5$ & 37 & $-0.03,4.3$ & NS \\
\hline
\end{tabular}

$C l$, Confidence interval; $L V D D$, left ventricular diastolic diameter; $L V M I$, left ventricular mass index; $F S$, fractional shortening; $L V O T$, left ventricular outflow tract; VTI, velocity time integral; $N S$, not significant.

would suggest that a larger Mosaic valve might be implanted. However, in our study the label sizes were similar. By contrast, in the study by Seitelberger and associates, ${ }^{6}$ the Perimount valves tended to be smaller inasmuch as there were 10 Perimount but no Mosaic valves at label size 19. It is possible that there was an unintentional bias in favor of the Mosaic in the study of Seitelberger and coworkers. ${ }^{6}$ The body surface area of the patients was not given, but there were 8 patients with a $19-\mathrm{mm}$ tissue annulus diameter as measured by an independent sizer and all of these were implanted with a Perimount valve. On the other hand, our study could have been biased toward the Perimount valve if the label size of the Mosaic valve was limited not by the tissue annulus but by the size of the aortic root, as occurs with other supraannular valves. $^{24}$

The overriding concern in research in the past has been the objective assessment of hemodynamic function and clinical event rates including mortality. What also matters to a patient is exercise ability and quality of life. The minor hemodynamic difference did not translate to any difference in exercise ability, although after surgery both groups had large and clinically significant improvements compared with preoperative levels. The 6-minute walk is a simple physiologic

TABLE 6a. Hospital and anxiety questionnaire (mean \pm standard deviation)

\begin{tabular}{lccccc}
\hline & Mosaic & $\mathbf{N}$ & Perimount & $\mathbf{N}$ & $\boldsymbol{P}$ value \\
\hline Anxiety (pre) & $7.2 \pm 3.7$ & 46 & $7.6 \pm 4.4$ & 47 & NS \\
Anxiety (12 mo) & $5.0 \pm 3.0$ & 40 & $4.2 \pm 3.7$ & 38 & NS \\
P value & .001 & & $<.0001$ & & \\
Depression (pre) & $5.9 \pm 3.5$ & 46 & $6.1 \pm 4.1$ & 47 & NS \\
Depression (12 mo) & $4.4 \pm 2.8$ & 40 & $4.4 \pm 3.7$ & 37 & NS \\
$P$ value & .003 & & $\mathbf{. 0 3 2}$ & & \\
\hline
\end{tabular}

$N S$, Not significant. measure of exercise capacity that can be performed by most patients. It is likely to be more representative than the NYHA class. Similarly, both groups showed large improvement in anxiety and depression scores using the Hospital Anxiety and Depression scale and in mental and physical scores using the SF-36 questionnaire. The improvement was predominantly in physical score (12.8 for the Perimount valve and 10.2 for the Mosaic valve) rather than the mental composite score (4.7 for the Perimount valve and 3.5 for the Mosaic valve). Little previously published work exists, but our results are consistent with Ware and Kosinski's ${ }^{25}$ estimation of mental and physical composite scores from a study of 94 patients having valve surgery. ${ }^{26}$ They showed that an improvement in score at 6 months after surgery occurred mainly for the physical score (7.6 points) rather than the mental score (3.2 points). However, this may be because the mental score was less reduced before surgery than the physical score. In our study, both scores were similar after surgery to the expected normal range, which for a US population aged older than 75 years is 37.9 (SD 11.2) for physical and 50.4 (SD 11.7) for mental score. ${ }^{9}$ We also showed significant improvements in both the depression and anxiety scores

TABLE 6b. SF-36 questionnaire (mean \pm standard deviation)

\begin{tabular}{lccccc}
\hline & Mosaic $^{\mathrm{TM}}$ & $\mathbf{N}$ & Perimount $^{\mathrm{TM}}$ & $\mathbf{N}$ & $\boldsymbol{P}_{\text {value }}$ \\
\hline PCS (pre) & $28.1 \pm 11.8$ & 46 & $26.0 \pm 9.9$ & 46 & NS \\
PCS (12 mo) & $38.3 \pm 11.7$ & 38 & $38.8 \pm 12.03$ & 38 & NS \\
P value & $<.0001$ & & $<.0001$ & & \\
MCS (pre) & $47.6 \pm 10.8$ & 46 & $45.2 \pm 11.8$ & 47 & NS \\
MCS (12 mo) & $51.1 \pm 8.6$ & 38 & $49.9 \pm 12.6$ & 38 & NS \\
P value &. $\mathbf{0 0 5}$ & & $\mathbf{. 0 0 9}$ & & \\
\hline
\end{tabular}

SF-36, Short Form-36; PCS, Physical composite score; MCS, mental composite score; $N S$, not significant. 
of the Hospital Anxiety and Depression scale. However, for none of these functional measures was there any difference between the two valve types.

\section{Clinical Implications}

There is general agreement that patient-prosthesis mismatch has adverse clinical effects, particularly in patients with impaired LV function. ${ }^{27-29}$ Despite this, we found no difference in exercise capacity or regression of LV hypertrophy although our patients were observed only to 1 year. It is also possible that valves with a larger effective orifice area will allow patients to avoid symptoms for longer as progressive stenosis develops as a result of primary valve failure. This could reduce the risk of cardiac events and reoperation in the long term.

\section{Limitations}

This study reports information to only 1 year, and it is possible that late event rates or durability may differ. Furthermore, the study was primarily concerned with hemodynamic function and was not powered to detect small differences in event rates. There was a trend in effective orifice area in favor of the Perimount valve, which might have been statistically significant with a larger population size. It is also possible that the hemodynamic differences might have been greater had we been able to use the Carpentier-Edwards Perimount Magna valve (Edwards Lifesciences, Irvine, Calif), which is a wholly supra-annular version of the Perimount design. However, a comparison of the Perimount Magna with the Mosaic ${ }^{30}$ found a mean pressure difference of 10.2 versus $17.1 \mathrm{~mm}$ $\mathrm{Hg}$, which is similar to our results (11 vs $17 \mathrm{~mm} \mathrm{Hg}$ ). Although all surviving patients were studied immediately after surgery, 22 subjects could not have echocardiography at 1 year. Despite this, the hemodynamic results were similar at both time points.

\section{Conclusion}

In this randomized comparison of the Mosaic and Perimount valves, there were minor differences in hemodynamic function in favor of the Perimount valve. Both valves were associated with similar and significant improvements in quality of life, exercise ability, and regression of LV mass.

\section{References}

1. Gonzalez-Juanatey JR, Garcia-Bengoechea JB, Vega M, Rubio J, Sierra J, Duran D, et al. Echocardiographic features of the normofunctioning Labcor-Santiago pericardial bioprosthesis. J Heart Valve Dis. 1994;3:548-55.

2. Dumesnil JG, Honos GN, Lemieux M, Beauchemin J. Validation and application of indexed aortic prosthetic valve areas calculated by Doppler echocardiography. J Am Coll Cardiol. 1990;16:637-43.

3. Williams GA, Labovitz AJ. Doppler hemodynamic evaluation of prosthetic (Starr-Edwards and Björk-Shiley) and bioprosthetic (Hancock and Carpentier-Edwards) cardiac valves. Am J Cardiol. 1985;56: 325-32.

4. Cochran R, Kunzelman K. Discrepancies between labeled and actual dimensions of prosthetic valves and sizers. Card Surg. 1996;11:318-24.
5. Eichinger WB, Botzenhardt F, Keithahn A, Guenzinger R, Bleiziffer S, Wagner I, et al. Exercise hemodynamics of bovine versus porcine bioprostheses: a prospective randomized comparison of the Mosaic and Perimount aortic valves. J Thorac Cardiovasc Surg. 2005;129: 1056-63.

6. Seitelberger R, Bialy J, Gottardi R, Gernot Seebacher, Reinhard Moidl, Martina Mittelböck, et al. Relation between size of prosthetic and valve gradient: comparison of two aortic bioprosthesis. Eur J Cardiothorac Surg. 2004;25:358-63.

7. Sahn DJ, De Maria A, Kisslo J. Weyman AE, the Committee on M-mode Standardization of the American Society of Echocardiography. Recommendations regarding quantitation in M-mode echocardiography: results of a survey of echocardiographic measurements. Circulation. 1978;58: 1072-81.

8. Edmunds LH, Clark RE, Cohn LH, Grunkemeier GL, Miller DC, Weisel RD. Guidelines for reporting morbidity and mortality after cardiac valvular operations. Ann Thorac Surg. 1996;62:932-5.

9. Ware JE. Conceptualizing and measuring generic health outcomes. Cancer. 1991;67:774-9.

10. Stewart AL, Ware JE, eds. Measuring functioning and well-being. Durham: Duke University Press; 1992.

11. Zigmond AS, Snaith RP. The hospital anxiety and depression scale. Acta Psychiat Scand. 1983;67:61-70.

12. Butland RJA, Pang J, Gross ER, Woodcock AA, Geddes EM. Two-, six-, and 12-minute walking tests in respiratory disease. $\mathrm{Br}$ Med $\mathrm{J}$. $1982 ; 284: 1607-8$

13. Mullaby CJ, Schaff HV, Orszlak TA, Miller FA. Early clinical and hemodynamic evaluation of aortic Intact porcine bioprosthesis. J Heart Valve Dis. 1994;3:641-7.

14. Eichinger WB, Schutz A, Simmerl D, Gansera BU, Breuer M, Haslinger B, et al. The Mosaic bioprosthesis in the aortic position: hemodynamic performance after 2 years. Ann Thorac Surg. 1998;66: S126-9.

15. Jamieson WR, Janusz MT, MacNab J, Henderson C. Hemodynamic comparison of second- and third-generation stented bioprosthetses in aortic valve replacement. Ann Thorac Surg. 2001;71:S282-4.

16. Corbineau H, Lelong B, Langanay T, Verhoye JP, Leguerrier A. Echocardiographic assessment and preliminary clinical results after aortic valve replacement with the Medtronic Mosaic bioprosthesis. $J$ Heart Valve Dis. 2001;10:171-6.

17. Eichinger W, Gunzinger R, Botzenhardt F, Simmerl D, Gansera B, Kemkes BM. The Mosaic bioprosthesis in the aortic position at five years. J Heart Valve Dis. 2000;9:653-60.

18. Fradet GJ, Bleese N, Busse E, Jamieson E, Raudkivi P, Goldstein J, et al. The Mosaic valve clinical performance at seven years: results from a multicenter prospective clinical trial. J Heart Valve Dis. 2004;13: $239-46$.

19. Thomson DJ, Jamieson WRE, Dumesnil JG, Burgess JJ, Peniston CM, Metras J, et al. Medtronic Mosaic porcine bioprosthesis: midterm investigational trial results. Ann Thorac Surg. 2001;71:S269-72.

20. Wong SP, Leggett ME, Greaves SC, Barratt-Boyes BG, Milsom FP, Raudkivi PJ. Early experience with the Mosaic bioprosthesis: a new generation porcine valve. Ann Thorac Surg. 2000;69:1846-50.

21. Gansera B, Botzenhardt F, Gunzinger R, Spiliopoulos K, Angelis I, Kemkes BM. The Mosaic bioprosthesis in the aortic position: seven years' results. J Heart Valve Dis. 2003;12:354-61.

22. Walther T, Lehmann S, Fal V, Metz S, Doll N, Rastan A, et al. Prospectively randomized evaluation of stented xenograft hemodynamic function in the aortic position. Circulation. 2004;110(11 Suppl 1):II74-8.

23. Dellgren G, David TE, Raanani E, Armstrong S, Ivanov J, Rakowski H. Late hemodynamic and clinical outcomes of aortic valve replacement with the Carpentier-Edwards Perimount pericardial bioprosthesis. J Thorac Cardiovasc Surg. 2002;124:146-54.

24. Chambers J, Roxburgh J, Blauth C, O'Riordan J, Hodson F, Rimington $\mathrm{H}$. A randomized comparison of the MCRI On-X and Carbomedics "Top Hat" bileaflet mechanical replacement aortic valves: early postoperative hemodynamic function and clinical events. J Thorac Cardiovasc Surg. 2005;130:759-64.

25. Ware JE, Kosinski M. SF-36 Physical and Mental Health Summary Scales: a manual for users of version 1, 2nd ed. QualityMetric Incorporated: Lincoln [RI]; 2001. ISBN 1-891810-09-X. 
26. Phillips RC, Lansky DJ. Outcomes management in heart valve replacement surgery: early experience. J Heart Valve Dis. 1992;1:42-50.

27. Blais C, Dumesnil JG, Baillot R, Simard S, Doyle D, Pibarot P. Impact of prosthesis-patient mismatch on short-term mortality after aortic valve replacement. Circulation. 2003;108:983-8.

28. Tasca G, Mhagna Z, Perotti S, Centurini PB, Sabatini T, Amaducci A, et al. Impact of prosthesis-patient mismatch on cardiac events and midterm mortality after aortic valve replacement in patients with pure aortic stenosis. Circulation. 2006;113:570-6.
29. Mohty D, Malouf JF, Girard SE, Schaff HV, Grill DE, EnriquezSarano ME, et al. Impact of prosthesis-patient mismatch on long-term survival in patients with small St. Jude Medical mechanical prostheses in the aortic position. Circulation. 2006;113:420-6.

30. Dalmau MJ, Maria Gonzalez-Santos J, Lopez-Rodriguez J, Bueno M, Arribas A, Nieto F. One year hemodynamic performance of the Perimount Magna pericardial xenograft and the Medtronic Mosaic bioprosthesis in the aortic position: a prospective randomized study. Interact Cardiovasc Thorac Surg. 2007;6:345-9. 